\title{
Growth inhibitory and apoptosis-inducing effects of allergen-free Rhus verniciflua Stokes extract on A549 human lung cancer cells
}

\author{
IK-SOON JANG $^{1 *}$, JAE-WOO PARK $^{2 *}$, EUN-BI JO $^{1 *}$, CHONG-KWAN CHO $^{2}$, YEON-WEOL LEE ${ }^{2}$, \\ HWA-SEUNG YOO ${ }^{2}$, JUNSOO PARK ${ }^{3}$, JIHYE KIM ${ }^{4}$, BYEONG-CHURL JANG ${ }^{4}$ and JONG-SOON CHOI ${ }^{1,5}$ \\ ${ }^{1}$ Division of Bioconvergence, Korea Basic Science Institute, Daejeon 305-333; ${ }^{2}$ East-West Cancer Center, Daejeon University, \\ Daejeon 302-120; ${ }^{3}$ Division of Biological Science and Technology, Yonsei University, Wonju 220-100; \\ ${ }^{4}$ Department of Molecular Medicine, College of Medicine, Keimyung University, Daegu 704-701; \\ ${ }^{5}$ Graduate School of Analytical Science and Technology, Chungnam National University, \\ Daejeon 305-764, Republic of Korea
}

Received March 4, 2016; Accepted May 20, 2016

DOI: 10.3892/or.2016.5131

\begin{abstract}
Evidence suggests that Rhus verniciflua Stokes (RVS) or its extract has the potential to be used for the treatment of inflammatory and neoplastic diseases. However, direct use of RVS or its extract as a herbal medicine has been limited due to the presence of urushiol, an allergenic toxin. In the present study, we prepared an extract of the allergen-removed RVS (aRVS) based on a traditional method and investigated its inhibitory effect on the growth of various types of human cancer cells, including lung (A549), breast (MCF-7) and prostate (DU-145) cancer cell lines. Notably, among the cell lines tested, treatment with the aRVS extract strongly inhibited proliferation of the A549 cells at a $0.5 \mathrm{mg} /$ $\mathrm{ml}$ concentration for $24 \mathrm{~h}$ that was not cytotoxic to normal human dermal fibroblasts. Furthermore, aRVS extract treatment largely reduced the survival and induced apoptosis of the A549 cells. At the mechanistic levels, treatment with the aRVS extract led to the downregulation of Bcl-2 and Mcl-1 proteins, the activation of caspase-9/-3 proteins, an increase in cytosolic cytochrome $c$ levels, the upregulation of Bax protein, an increase in phosphorylated p53 protein but a decrease in phosphorylated S6 protein in the A549 cells. Importantly, treatment with z-VAD-fmk, a pan-caspase inhibitor attenuated
\end{abstract}

Correspondence to: Dr Byeong-Churl Jang, Department of Molecular Medicine, College of Medicine, Keimyung University, 1095 Dalgubeoldaero, Dalseo-gu, Daegu 704-701, Republic of Korea E-mail: jangbc123@gw.kmu.ac.kr

Dr Jong-Soon Choi, Division of Bioconvergence, Korea Basic Science Institute, 169-148 Gwahak-ro, Yuseong-gu, Daejeon 305-333, Republic of Korea

E-mail: jschoi@kbsi.re.kr

*Contributed equally

Key words: allergen-removed Rhus verniciflua Stokes extract, A549, caspase, apoptosis, Bcl-2
aRVS extract-induced apoptosis in the A549 cells. These results demonstrate firstly that aRVS extract has growth inhibitory and apoptosis-inducing effects on A549 human lung cancer cells through modulation of the expression levels and/or activities of caspases, Bcl-2, Mcl-1, Bax, p53 and S6.

\section{Introduction}

Rhus verniciflua Stokes (RVS) renamed as Toxicodendron vernicifluum belongs to the Anacardiaceae family, commonly known as the lacquer tree. RVS has been traditionally used as an herbal medicine in East Asian countries for the treatment of gastritis, stomach cancer and atherosclerosis $(1,2)$. RVS contains compounds such as gallic and protocatechuic acids, quercetin, fustin, fisetin, sulfuretin and butein. There is increasing evidence that RVS extract and its components have antioxidant, anti-inflammatory and/or anticancerous activities (3-6). Numerous in vitro and in vivo studies have further shown the antitumor effects of the RVS extract and/or its components on various human cancer types or cell lines, including stomach, breast and liver cancer, osteosarcoma and lymphoma (7-10). Possible mechanisms underlying the antitumor effects of the RVS extract and/or its components have also been previously reported, including induction of apoptosis and inhibition of the phosphoinositol-3-kinase (PI3K)-Akt/protein kinase B (PKB) pathway (7), activation of the AMP-activated protein kinase (AMPK) (11), cell cycle arrest (12) and reduction of manganese superoxidase (MnSOD) activity or glutathione (GSH) content (13).

However, herbal medicinal/pharmacological use of RVS or its extract has been limited due to the presence of an allergenic substance, urushiol (a mixture of several derivatives of catechol) which causes severe contact dermatitis in sensitive individuals $(8,14)$. It is therefore proposed that removal of urushiol from RVS or its extract is required for its pharmacological or medicinal uses. Accordingly, it has been shown that a standardized extract of the allergen-free RVS is efficacious for the treatment of advanced or metastatic cancers (10). Although numerous studies have been published 
concerning the antitumor effect of the allergen-free RVS extract, molecular and cellular mechanisms by which the allergen-free RVS extract exerts its anti-growth and/or apoptosis-inducing effects on human cancer cells are still not fully understood at present.

In the present study, we prepared an extract of the allergen-removed RVS (aRVS) based on a traditional method and investigated its effect on the growth of various human cancer cells, including lung (A549), breast (MCF-7) and prostate (DU-145) cancer cell lines. In the present study, we report for the first time that aRSV extract has strong antiproliferative, anti-survival and pro-apoptotic effects on A549 human lung cancer cells and the effects are mediated through modulation of the expression levels and/or activities of caspase-9/-3, Bcl-2, Mcl-1, Bax, p53 and S6.

\section{Materials and methods}

Reagents and chemicals. Fetal bovine serum (FBS), 4-(2-hydroxyethyl)-1-piperazineethanesulfonic (HEPES), L-glutamate, $1 \%(\mathrm{w} / \mathrm{v})$ penicillin-streptomycin and phosphate-buffered saline (PBS) were obtained from Gibco (Paisley, Scotland, UK). Dulbecco's modified Eagle's medium (DMEM), Roswell Park Memorial Institute (RPMI)-1640 medium and anti-actin mouse monoclonal antibody were purchased from Sigma-Aldrich (St. Louis, MO, USA). Cell culture dishes were purchased from Nunc (Roskilde, Denmark). An Annexin V-FLUOS staining kit was provided by Roche Diagnostics GmbH (Mannheim, Germany). Enzyme-linked chemiluminescence (ECL) western detection reagents were purchased from Thermo Scientific (Waltham, MA, USA). Bradford reagent was purchased from Bio-Rad (Hercules, CA, USA). $N$-benzyloxycarbonyl-Val-Ala-Asp-fluoromethylketone (z-VAD-fmk) and a protease inhibitor cocktail (100X) were purchased from Calbiochem (Madison, WI, USA). Antibodies for procaspase-9 and -3 were purchased from Stressgen (Ann Arbor, MI, USA). Antibodies for B-cell lymphoma-2 (Bcl-2) and myeloid cell leukemia-1 (Mcl-1), Bcl-2-associated X protein (Bax), phosphorylated (p)-p53, total (T)-p53, p-S6, T-S6, HuR and cytochrome $c$ were purchased from Santa Cruz Biotechnology (Santa Cruz, CA, USA). An antibody for poly(ADP-ribose) polymerase (PARP) was purchased from Roche (Basel, Switzerland). An antibody for extracellular signal regulated kinase-1/2 (ERK-1/2) was purchased from Epitomics (Burlingame, CA, USA).

Preparation of the aRVS extract. $R$. verniciflua Stokes (RVS) was purchased from Chamotdeul Co., Ltd. (Okcheon, Chungcheongbuk-do, Korea). In the commercial preparation, 8 -year-old Rhus trees were collected and dried during winter. The barks containing the toxic substance urushiol were extracted from the wood by treatment with ceramic water. The wood was then naturally dried in a field setting. After pulverizing the chopped wood into small pieces and converting it to powder, the powder samples were added to a heat-treated drying hopper. The preparation procedure was conducted according to the protocol of the Agricultural Corporation OTSAM (Okcheon, Chungcheongbuk-do, Korea). After pretreatment, the non-woven, packed Rhus powder was extracted with purified water in a $1: 2(\mathrm{w} / \mathrm{v})$ ratio in a 501 pilot extractor at $121^{\circ} \mathrm{C}$ and $1.2 \mathrm{~kg} / \mathrm{cm}^{2}$ for $24 \mathrm{~h}$. The aRVS-containing flavonoids obtained from $75 \mathrm{~g}$ of Rhus extract powder were extracted in $1,500 \mathrm{l}$ of water at $121^{\circ} \mathrm{C}$ and $1.2 \mathrm{~kg} / \mathrm{cm}^{2}$ for $2 \mathrm{~h}$. The extract was filtered using a $1 \mathrm{~mm}$ filtration device and concentrated to 15 degrees Brix $\left({ }^{\circ} \mathrm{Bx}\right)$ at $60^{\circ} \mathrm{C}$ for $4 \mathrm{~h}$ at a pressure of $760 \mathrm{mmHg}$. The purified aRVS was kept refrigerated at $10^{\circ} \mathrm{C}$ prior to experimentation.

Cell culture. A549 human lung carcinoma, MCF-7 human breast cancer and DU-145 human prostate cancer cells, and normal human diploid fibroblasts (HDF) were grown in DMEM supplemented with $10 \%$ (v/v) FBS and $1 \%(\mathrm{w} / \mathrm{v})$ penicillin-streptomycin with $5 \%(\mathrm{v} / \mathrm{v}) \mathrm{CO}_{2}$ in a $37^{\circ} \mathrm{C}$ humidified incubator. Respective cells were allowed to adhere and grown for $24 \mathrm{~h}$ prior to treatment with the aRVS extract.

Cell viability assay. Cell viability assay was performed as previously described (12). Briefly, respective human cancer cells and normal HDF were seeded at a density of $5 \times 10^{3}$ cells/well in a 96-well plate. After $24 \mathrm{~h}$ of incubation, tester cells were treated with the aRVS extract at a given concentration. The optimal dose not affecting cytotoxicity was determined and evaluated using the Cell Counting Kit-8 solution (Dojindo, Gaithersburg, MD, USA). The aRVS powder was applied for pretreatment at concentrations of $0,0.125,0.25,0.5$ or $1 \mathrm{mg} / \mathrm{ml}$ for $24 \mathrm{~h}$. Relative absorbance of cell viability was measured at $450 \mathrm{~nm}$ using a Sunrise microplate absorbance reader (Tecan, Männedorf, Switzerland) and evaluated in triplicate experiments compared with the untreated control.

Cell count assay and cell morphological analysis. A549 cells were seeded in 24-well plates and treated without or with different concentrations of aRVS extract for $24 \mathrm{~h}$. The number of surviving cells, which cannot be stained with trypan blue dye, were counted using standard light microscopy. Approximately, $<100$ cells were counted for the analysis. The cell count assay was carried out in triplicate. Data are expressed as the mean \pm standard error (SE) of three independent experiments. Survival is expressed as a percentage of the control. Phase contrast images of the conditioned cells were also captured by an Olympus phase contrast microscope equipped with a digital camera (Nikon).

Propidium iodide (PI)-Annexin V staining. Apoptosis was detected by PI-Annexin V staining using an Annexin V-FLUOS Staining kit according to the manufacturer's instructions. The detailed procedure has been previously described (13).

Preparation of whole cell lysates. Untreated or aRVS-treated A549 cells were washed with PBS and exposed to cell lysis buffer [50 mM Tris-Cl (pH 7.4), $150 \mathrm{mM} \mathrm{NaCl}, 0.1 \%$ sodium dodecyl sulfate, $0.25 \%$ sodium deoxycholate, $1 \%$ Triton X-100, $1 \%$ Nonidet P-40, 1 mM EDTA, 1 mM EGTA and protease inhibitor cocktail $(1 \mathrm{X})]$. The cell lysates were collected in a $1.5 \mathrm{ml}$ tube and centrifuged for $20 \mathrm{~min}$ at $4^{\circ} \mathrm{C}$ at $12,000 \mathrm{rpm}$. The supernatant was saved and the protein concentrations were determined using Bradford reagent.

Western blot analysis. Proteins $(50 \mu \mathrm{g})$ were separated by SDS-PAGE (10\%) and transferred onto nitrocellulose 

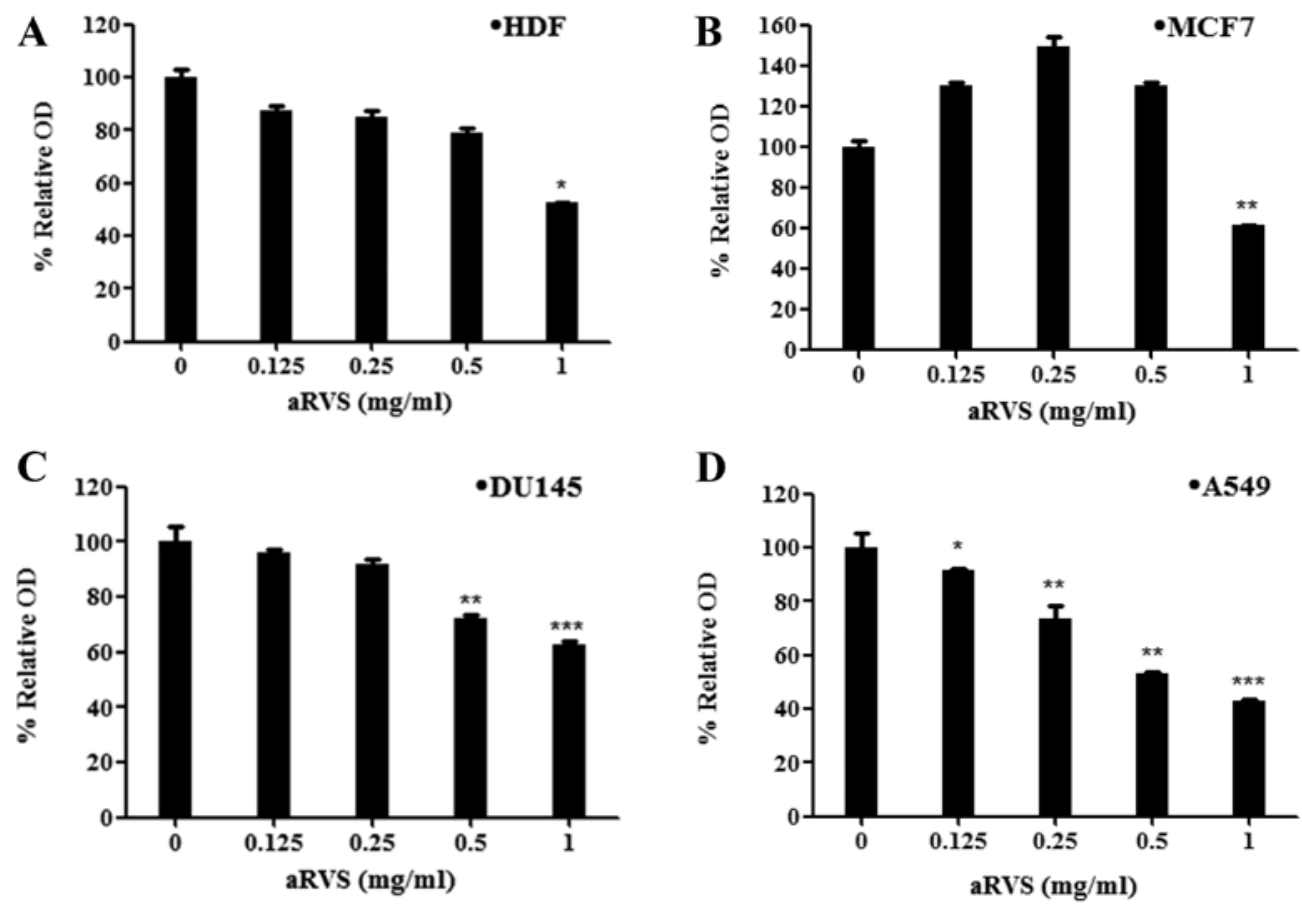

Figure 1. Effects of the aRVS extract on the proliferation of various human cancer cell lines. (A-D) Normal human diploid fibroblasts (HDF) (A), MCF-7 (breast cancer) (B), DU-145 (prostate cancer) (C) or A549 (lung cancer) (D) cells were treated with or without the indicated concentrations of the aRVS extract for $24 \mathrm{~h}$. Data are expressed as the mean $\pm \mathrm{SD}$, and statistical significance was considered at ${ }^{*} \mathrm{p}<0.05,{ }^{* *} \mathrm{p}<0.01$ and ${ }^{* * * *} \mathrm{p}<0.001 \mathrm{vs}$. the control. OD, optical density.

membranes (Millipore, Billerica, MA, USA). The membranes were washed with TBS (10 mM Tris, $150 \mathrm{mM} \mathrm{NaCl})$ supplemented with $0.05 \%$ (vol/vol) Tween-20 (TBST) followed by blocking with TBST containing 5\% (w/v) non-fat dried milk. The membranes were incubated overnight with antibodies specific for the protein of interest at $4^{\circ} \mathrm{C}$. The membranes were exposed to secondary antibodies coupled to horseradish peroxidase at room temperature for $2 \mathrm{~h}$. The membranes were washed, and immunoreactivities were detected by enzyme-linked chemiluminescence (ECL) reagents. The relative expression levels of target proteins to actin as the loading control protein were quantitatively analyzed using a densitometer.

Subcellular fractionation. To observe the treatment effect of the aRVS extract on the mobilization of cytochrome $c$ from the mitochondria to the cytosol, A549 cells $\left(0.5 \times 10^{6} / 2 \mathrm{ml} /\right.$ well $)$ were seeded in 6-well plates the day before the aRVS extract treatment. The cells were treated without or with aRVS extract $(0.5 \mathrm{mg} / \mathrm{ml})$ for $24 \mathrm{~h}$. The control or the aRVS extract-treated cells were then washed in PBS and successively extracted as described. First, the cells were extracted with buffer A $[10 \mathrm{mM}$ Tris-Cl (pH 7.5), $10 \mathrm{mM} \mathrm{NaCl}, 3 \mathrm{mM} \mathrm{MgCl} 2,0.5 \%(\mathrm{v} / \mathrm{v})$ Nonidet P-40, $1 \mathrm{mM}$ DTT]. The sample was then centrifuged and the resultant supernatant was saved as cytosolic proteins. The remaining pellet was washed in the same buffer $\mathrm{A}$ and then extracted in buffer B (10 mM Tris- $\mathrm{HCl}(\mathrm{pH} 7.5), 0.5 \mathrm{M}$ $\mathrm{NaCl}, 3 \mathrm{mM} \mathrm{MgCl}$, $0.5 \%$ (v/v) Nonidet P-40, $1 \mathrm{mM}$ DTT) to obtain nuclear proteins.

Measurement of DNA fragmentation. A549 cells were seeded in a $60-\mathrm{mm}$ dish and treated with or without the aRVS extract in the absence or presence of z-VAD-fmk for
$24 \mathrm{~h}$. The conditioned cells were harvested, washed and lysed in a buffer [50 mM Tris ( $\mathrm{pH} 8.0), 0.5 \%$ sarkosyl, $0.5 \mathrm{mg} / \mathrm{ml}$ proteinase $\mathrm{K}$ and $1 \mathrm{mM} \mathrm{EDTA}]$ at $55^{\circ} \mathrm{C}$ for $3 \mathrm{~h}$, followed by the addition of RNase $\mathrm{A}(0.5 \mu \mathrm{g} / \mathrm{ml})$ and incubation at $55^{\circ} \mathrm{C}$ for $18 \mathrm{~h}$. The lysates were centrifuged at $10,000 \mathrm{x} \mathrm{g}$ for $20 \mathrm{~min}$. Genomic DNA was extracted with equal volumes of a neutral phenol-chloroform-isoamyl alcohol mixture (25:24:1), and analyzed by electrophoresis on a $1.8 \%$ agarose gel. The DNA was visualized and photographed under UV illumination after staining with ethidium bromide.

Statistical analyses. GraphPad Prism (GraphPad, San Diego, CA, USA) was used for the statistical analysis of the cell proliferation assay. The assay was processed for the assessment of differences between the aRVS extract-treated and control groups by Student's t-test. The values are expressed as the mean \pm standard deviation (SD). Statistical significance was evaluated by p-values at $0.001,0.01$ and 0.05 . Cell count analysis was carried out in triplicate. Data are expressed as the mean \pm standard error $(\mathrm{SE})$. Significance $(\mathrm{p}<0.05)$ was determined by one-way ANOVA.

\section{Results}

The aRVS extract has strong antiproliferative activity in the A549 and DU145 cancer cells. Initially, we investigated the treatment effect of the aRVS extract at different concentrations for $24 \mathrm{~h}$ on the proliferation of various human cancer cell lines, including A549 (lung cancer), MCF-7 (breast cancer) or DU-145 (prostate cancer), by MTS-based cell proliferation analysis. In the present study, normal HDFs were also included to assess the effects of the aRVS extract on normal cell proliferation (Fig. 1A). Treatment with the aRVS extract 

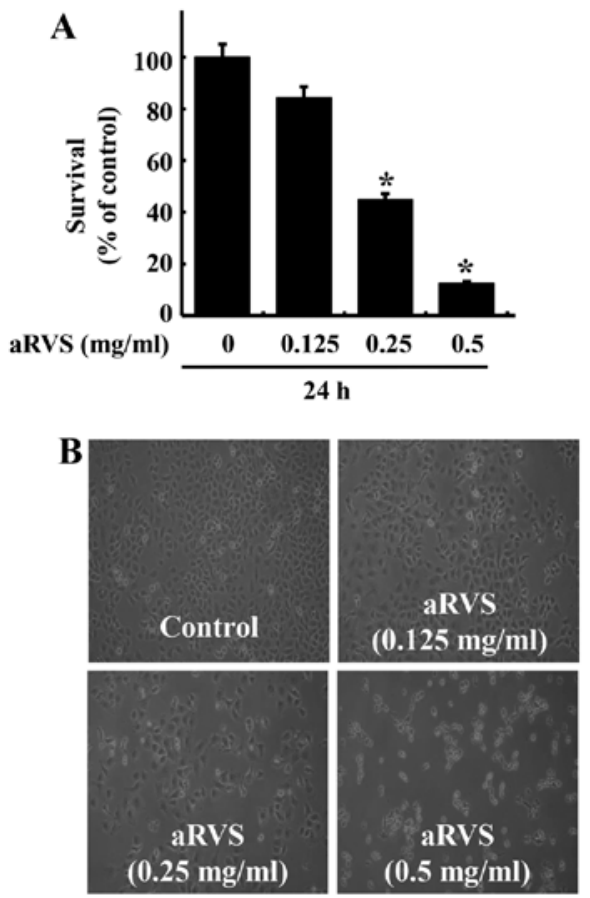

C

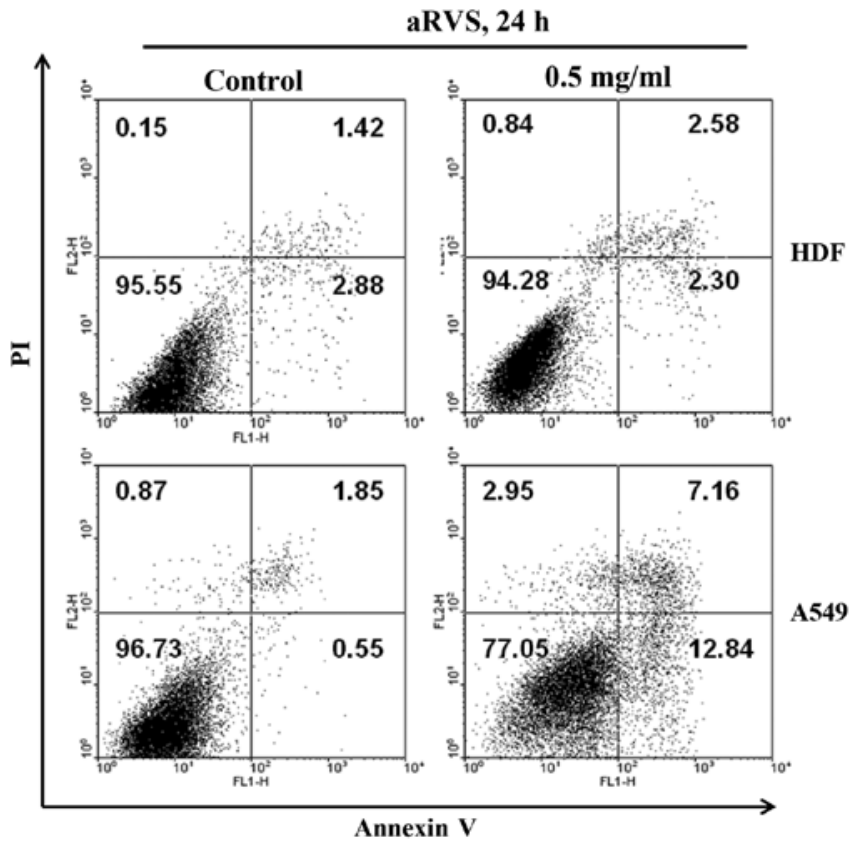

Figure 2. Effects of the aRVS extract on the survival and apoptosis of A549 lung cancer cells. (A) A549 cells were treated with or without the indicated concentrations of the aRVS extract for $24 \mathrm{~h}$. The number of surviving cells, which cannot be stained with trypan blue dye was counted under the microscope. The cell count assay was carried out in triplicate. Data are expressed as the mean $\pm \mathrm{SE}$ of three independent experiments. ${ }^{*} \mathrm{P}<0.05$ was compared to the value of the aRVS extract-free control. (B) A549 cells were treated with or without the indicated concentrations of the aRVS extract for $24 \mathrm{~h}$. Images of the conditioned cells were obtained by phase contrast microscopy (magnification, $\mathrm{x} 400$ ). Each image is a representation of three independent experiments. (C) Normal HDF or A549 cells were untreated (control) and treated with $0.5 \mathrm{mg} / \mathrm{ml}$ of the aRVS extract for $24 \mathrm{~h}$. The conditioned cells were stained with Annexin V and PI, and then the apoptotic cells were analyzed by a dot-plot using flow cytometry. The numbers in the quadrants of each plot indicate the percentage of Annexin-positive (apoptotic) cells. The data shown are the representation of three independent experiments.

dose-dependently inhibited proliferation of the DU-145 and A549 cells as shown in Fig. 1C and D. Distinctly, the aRVS extract treatment at $0.125,0.25$ or $0.5 \mathrm{mg} / \mathrm{ml}$ enhanced proliferation of the MCF-7 cells (Fig. 1B), but treatment with the aRVS extract at $1.0 \mathrm{mg} / \mathrm{ml}$ led to a large decrease in the cell proliferation. Although treatment with the aRVS extract at $0.125,0.25$ or $0.5 \mathrm{mg} / \mathrm{ml}$ had little effect on proliferation of the HDFs, treatment with the aRVS extract at $1.0 \mathrm{mg} / \mathrm{ml}$ also largely decreased HDF proliferation. Due to the strong antiproliferative effect on the A549 cells and no cytotoxicity to normal HDFs, we chose the A549 cells and the $0.5 \mathrm{mg} / \mathrm{ml}$ concentration of the aRVS extract for further studies.

The aRVS extract has strong anti-survival and pro-apoptotic effects on the A549 cells. We next studied the treatment effect of the aRVS extract at different concentrations for $24 \mathrm{~h}$ on the survival of the A549 cells by cell count analysis. As shown in Fig. 2A, treatment with the aRVS extract led to a concentration-dependent decrease in survival of the A549 cells. Data from microscopic observation, as shown in Fig. 2B, also revealed that the aRVS extract concentration-dependently reduced the number of A549 cells. Seemingly, when exposed to aRVS extract, A549 cells began to detach from the surface of the culture plate and appeared buoyant and were altered from a round shape to a sharp form at the cell poles. We next determined the effect of the aRVS extract on the apoptosis of A549 cells by flow cytometry. For the evaluation of apoptosis herein, the relative proportion of non-viable cells was quantitatively measured as cells undergoing the early stage of apoptosis
(Annexin stained, non-disrupted cells) or as cells entering the late stage of apoptosis (disrupted or lysed cells) in response to the aRVS extract treatment. As shown in Fig. 2C, results of flow cytometry demonstrated that upon treatment with the aRVS extract at $0.5 \mathrm{mg} / \mathrm{ml}$ for $24 \mathrm{~h}$, many Annexin V-stained viable A549 cells were shifted to the early apoptotic stage (0.55-12.84\%), whereas apoptotic change of HDF was not observed $(2.88-2.30 \%)$.

The aRVS extract alters the expression levels and/or activities of proteins in the A549 cells. We next determined the treatment effect of the aRVS extract on the expression levels and/or activities of cancer cell growth- or apoptosis-related proteins in the A549 cells. As shown in Fig. 3A, treatment with the aRVS extract at $0.5 \mathrm{~g} / \mathrm{ml}$ led to downregulation of Bcl-2 and Mcl-1 proteins but upregulation of Bax protein in the A549 cells. Furthermore, there was an increase in the levels of the phosphorylated p53 protein but a decrease in the levels of phosphorylated S6 protein in the A549 cells treated with the aRVS extract. Fig. 3B are the densitometry data of Fig. 3A that show Bcl-2, Mcl-1 and Bax protein levels normalized to actin protein levels, and p-p53 and p-S6 protein levels normalized to total p53 and S6 protein levels, respectively.

The aRVS extract activates caspase-9/-3 in A549 cells, which is important for aRVS extract-induced apoptosis. We next investigated the treatment effect of the aRVS extract on the activity of caspase- 9 and -3 , other apoptosis-related proteins, in the A549 cells. In the present study, the degree of caspase 

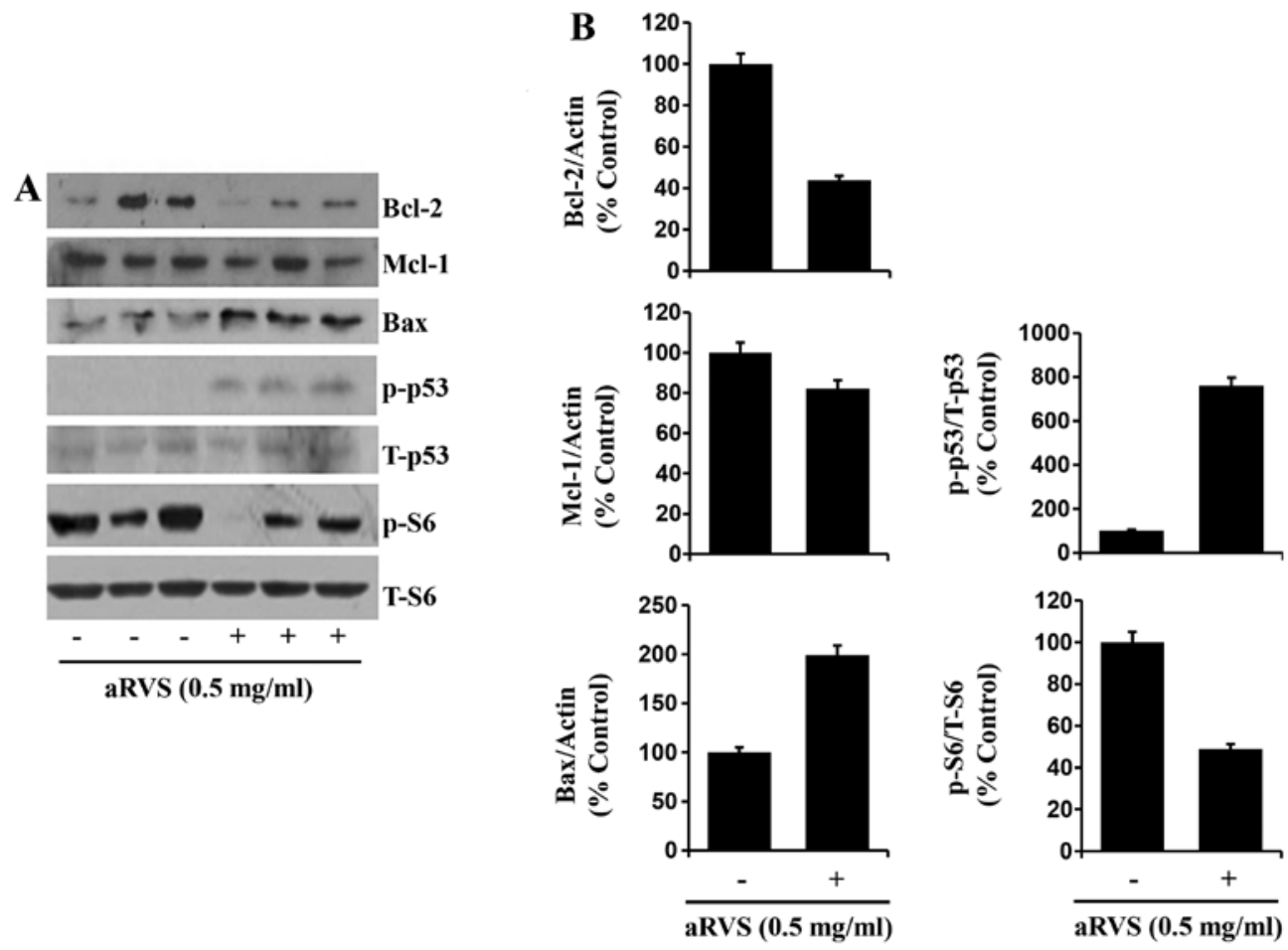

Figure 3. Effects of the aRVS extract on the expression of growth- and apoptosis-related proteins in the A549 cells. (A) A549 cells were treated with or without the aRVS extract $(0.5 \mathrm{mg} / \mathrm{ml})$ for $24 \mathrm{~h}$. Whole cell lysates from the conditioned cells were prepared and analyzed by western blotting. The image is a representation of three independent experiments. p-p53, phosphorylated p53; T-p53, total p53; p-S6, phosphorylated S6; and T-S6, total S6. (B) The densitometric data of (A) that show Bcl-2, Mcl-1 and Bax protein levels normalized to actin protein levels, and p-p53 and p-S6 protein levels normalized to total p53 and S6 protein levels, respectively.

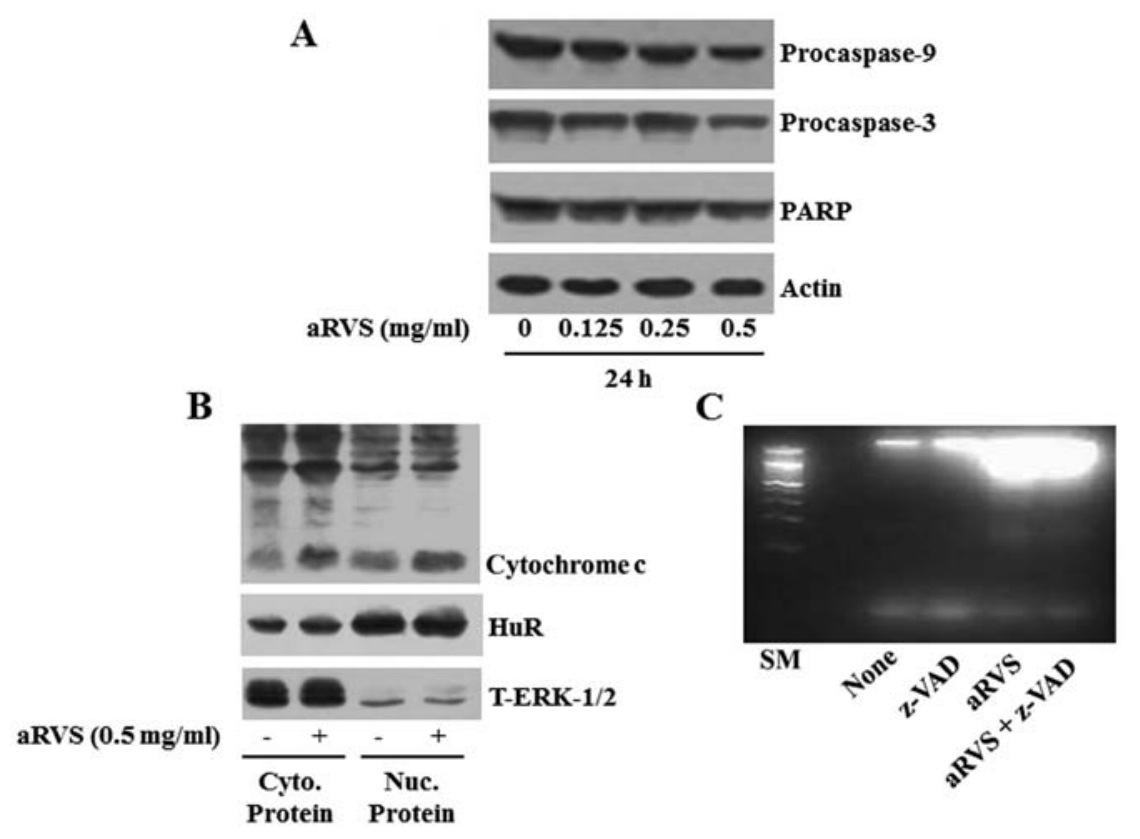

Figure 4. Effects of the aRVS extract and/or z-VAD-fmk on the activation of caspase-9/-3, release of cytosolic cytochrome $c$ and apoptosis in A549 cells. (A) A549 cells were treated with or without the indicated concentrations of the aRVS extract for $24 \mathrm{~h}$. Whole cell lysates from the conditioned cells were prepared and analyzed by western blotting. The image is a representation of three independent experiments. (B) A549 cells were treated with or without aRVS extract $(0.5 \mathrm{mg} / \mathrm{ml})$ for $24 \mathrm{~h}$. Cytosolic (Cyto.) and nuclear (Nuc.) protein fractions from the conditioned cells were subsequently extracted and analyzed by western blotting. The image is a representation of three independent experiments. (C) A549 cells were treated with or without the aRVS extract (0.5 mg/ml) in the absence or presence of z-VAD-fmk, a pan-caspase inhibitor for $24 \mathrm{~h}$. Extra-nuclear fragmented DNA from the conditioned cells was extracted, and analyzed on a $1.7 \%$ agarose gel. The image is a representation of three independent experiments. SM, DNA size marker.

activation by the aRVS extract in the A549 cells was assessed by decreased expression levels of procaspase- 9 or -3 (inactive form). As shown in Fig. 4A, treatment with the aRVS extract dose-dependently reduced expression levels of procaspase- 9 
and -3 in the A549 cells. PARP is a known downstream substrate of caspases. There was a dose-dependent decrease in the levels of PARP in the A549 cells treated with the aRVS extract for $24 \mathrm{~h}$, supporting the activation of caspases. We next carried out biochemical fractionation experiments (preparation of cytosolic and subsequent nuclear proteins) to observe the levels of cytosolic cytochrome $c$ in the A549 cells treated with the aRVS extract for $24 \mathrm{~h}$. As shown in Fig. 4B, treatment with the aRVS extract led to an increase in cytosolic cytochrome $c$ levels in the A549 cells. HuR is a nuclear protein but shuttles both the cytosolic and nuclear compartment in cells (15). ERK-1/2 is reported to be abundantly expressed in the cytosolic compartment (16). Low/high levels of HuR and high/low levels of ERK-1/2 in the cytosolic and nuclear fractions, respectively, suggest the fractionation efficiency. Using z-VAD-fmk, a pan-caspase inhibitor, we next determined the role of the activation of caspases in the aRVS extract-induced apoptosis of the A549 cells. As shown in Fig. 4C, aRVS extractinduced apoptosis of the A549 cells was strongly blocked in the presence of $\mathrm{z}-\mathrm{VAD}-\mathrm{fmk}$.

\section{Discussion}

RVS extract or a standardized extract of the allergen-free RVS is reported to have anticancer effects on several human cancers and/or cells, including stomach, breast and liver cancer, osteosarcoma and lymphoma (7,9-12). The efficacy and safety of a standardized allergen-free RVS extract as maintenance therapy in patients with advanced non-small cell lung cancer or pulmonary adenocarcinoma has also been previously reported (17). Regulation of human lung cancer cell growth and apoptosis by aRVS has not been previously reported. In the present study, we demonstrate for the first time that an extract of the allergen-removed Rhus verniciflua Stokes (aRVS) prepared using a traditional method has strong antiproliferative, antisurvival and pro-apoptotic effects on A549 human lung cancer cells. Our data also suggest that the anticancer effects of the aRVS extract on A549 cells are mediated through modulation of the expression levels and/or activities of caspase-9/-3, Bcl-2, Mcl-1, Bax, p53, and S6 proteins.

In initialexperiments, we demonstrated that the aRVS extract strongly inhibits proliferation and survival and also induces apoptosis of A549 cells (Figs. 1D, 2A-C and 4C), as evidenced by results from microscopic observation, PI-Annexin $\mathrm{V}$ staining and/or DNA fragmentation experiments. Induction of apoptosis is closely related to two pathways; the intrinsic (mitochondrial) pathway and the extrinsic (death receptor) pathway. Among the proteins involved in both these pathways mediating apoptosis, central to both apoptosis pathways are the caspases, a group of essential proteases required for the execution of cell death by apoptotic stimuli (18). It has also been demonstrated that in resting cells, caspases are synthesized as zymogens (inactive precursors), but upon exposure to apoptotic stimuli, they become processed via partial proteolytic cleavage and activated in cells (19) and that activated caspases participate in the cleavage of many target proteins, including PARP or PKC- $\delta$, and other vital proteins (20). Thus, the present findings that the aRVS extract induces activation of caspase-9/-3 (Fig. 4A) and increases cytosolic cytochrome $c$ levels (Fig. 4B) and that z-VAD-fmk, a pan-caspase inhibitor blocks aRVS extract-induced apoptosis (Fig. 4C) in the A549 cells strongly suggest that the activation of caspase-9/-3 through the intrinsic pathway is critical for the aRVS extract-induced apoptosis of the A549 cells.

An interesting finding of the present study is that the aRVS extract differentially regulated the expression of the family of Bcl-2 proteins, including Bcl-2, Mcl-1 and Bax in the A549 cells (Fig. 3A and B). Bcl-2 and Mcl-1 are pro-survival and anti-apoptotic proteins that are involved in apoptosis initiation and caspase activation by regulating the mitochondrial membrane integrity (21-23). In contrast, Bax is a pro-apoptotic protein that forms a heterodimer with $\mathrm{Bcl}-2$, and functions as an apoptotic activator $(23,24)$. It has also been shown that Bax interacts with, and increases the opening of, the mitochondrial voltage-dependent anion channel, which leads to the loss in membrane potential and the release of cytochrome $c$ (24-26). Thus, considering an RVS extract-mediated decrease in expression of Bcl-2 and Mcl-1, but an increase in the expression of Bax in the A549 cells (Fig. 3A and B), the present study suggests that both the loss of Bcl-2 and Mcl-1 and Bax upregulation may contribute to activation of the intrinsic caspase pathway, growth inhibition and/or apoptosis of A549 cells exposed to the aRVS extract.

Another notable finding in the present study is the ability of the aRVS extract to increase levels of phosphorylated p53 protein without affecting its total protein expression levels in the A549 cells (Fig. 3A and B). p53 is a tumor-suppressor and has been shown to mediate a variety of antiproliferative and/or pro-apoptotic processes in response to diverse forms of cellular stress $(27,28)$. Studies have recently demonstrated that apoptosis of the A549 cells is accompanied by p53 upregulation $(27,29)$ and siRNA-mediated p53 knockdown markedly reduces apoptosis of A549 cells (27), suggesting a role of p53 upregulation in cell apoptosis. It is thus speculative that an increase in phosphorylated p53 may further become a part of the aRVS extract-mediated anticancer effects on A549 cells. S6 is a ribosomal protein involved in protein synthesis $(30,31)$. Compelling evidence strongly suggests that hyperphosphorylation of the S6 protein is associated with increased growth or survival of cancer cells and is a therapeutic target in lung tumors $(31,32)$. In the present study, we demonstrated that the aRVS extract largely reduced levels of phosphorylated S6 protein in the A549 cells (Fig. 3A and B), which may indicate that S6 hypophosphorylation may also mediate or facilitate the anticancer effects of the aRVS extract on the A549 cells. Moreover, we demonstrated that in addition to the A549 lung cancer cells, the aRVS extract at a $0.5 \mathrm{mg} / \mathrm{ml}$ concentration also inhibited the growth of DU-145 prostate cancer cells (Fig. 1C). These results may have importance to state that the cancer cell growth inhibitory effect of the aRVS extract at $0.5 \mathrm{mg} / \mathrm{ml}$ is not restricted to A549 cells.

In summary, we firstly demonstrated that aRSV has strong anti-growth and pro-apoptotic effects on A549 human lung cancer cells and the effects are mediated through the activation of caspases, downregulation of Bcl-2 and Mcl-1, Bax upregulation, p53 hyperphosphorylation and S6 hypophosphorylation. Our findings presented here, may shed light on the possibility of applying an aRVS extract to the treatment of lung cancer, as a single and/or combinatorial regimen with other known anti-lung cancer therapies. 


\section{Acknowledgements}

The present study was supported by the National Research Foundation of Korea Grant funded by the Korean Government (MEST) (2013, University-Institute Cooperation Program) and also in part by the Korea Basic Science Institute NAP grant (T32780) and by the National Research Foundation of Korea (NRF) Grant funded by the Korean Government (MSIP) (no. 2014R1A5A2010008).

\section{References}

1. Hong DH, Han SB, Lee CW, Park SH, Jeon YJ, Kim MJ, Kwak SS and Kim HM: Cytotoxicity of urushiols isolated from sap of Korean lacquer tree (Rhus vernicifera Stokes). Arch Pharm Res 22: 638-641, 1999.

2. Choi KC, Chung WT, Kwon JK, Jang YS, Yu JY, Park SM and Lee JC: Chemoprevention of a flavonoid fraction from Rhus verniciflua Stokes on aflatoxin $\mathrm{B}_{1}$-induced hepatic damage in mice. J Appl Toxicol 31: 150-156, 2011.

3. Kim TJ: Korean Resources Plants II. Seoul National University Press, pp194-195, 1996.

4. Jung $\mathrm{CH}$, Jun $\mathrm{CY}$, Lee $\mathrm{S}$, Park $\mathrm{CH}$, Cho $\mathrm{K}$ and $\mathrm{Ko} \mathrm{SG}$ Rhus verniciflua Stokes extract: Radical scavenging activities and protective effects on $\mathrm{H}_{2} \mathrm{O}_{2}$-induced cytotoxicity in macrophage RAW 264.7 cell lines. Biol Pharm Bull 29: 1603-1607, 2006.

5. Lee JC, Lim KT and Jang YS: Identification of Rhus verniciflua Stokes compounds that exhibit free radical scavenging and antiapoptotic properties. Biochim Biophys Acta 1570: 181-191, 2002.

6. Jung $\mathrm{CH}$, Kim JH, Hong MH, Seog HM, Oh SH, Lee PJ, Kim GJ, Kim HM, Um JY and Ko SG: Phenolic-rich fraction from Rhus verniciflua Stokes (RVS) suppress inflammatory response via NF-kappaB and JNK pathway in lipopolysaccharide-induced RAW 264.7 macrophages. J Ethnopharmacol 110: 490-497, 2007.

7. Kim JH, Go HY, Jin DH, Kim HP, Hong MH, Chung WY, Park JH, Jang JB, Jung H, Shin YC, et al: Inhibition of the PI3K-Akt/PKB survival pathway enhanced an ethanol extract of Rhus verniciflua Stokes-induced apoptosis via a mitochondrial pathway in AGS gastric cancer cell lines. Cancer Lett 265: 197-205, 2008.

8. Powell SM and Barrett DK: An outbreak of contact dermatitis from Rhus verniciflua (Toxicodendron vernicifluum). Contact Dermat 14: 288-289, 1986.

9. Kitts DD and Lim KT: Antitumorigenic and cytotoxic properties of an ethanol extract derived from Rhus verniciflua Stokes (RVS). J Toxicol Environ Health A 64: 357-371, 2001.

10. Choi W, Jung H, Kim K, Lee S, Yoon S, Park J, Kim S, Cheon S, Eo $\mathrm{W}$ and Lee S: Rhus verniciflua Stokes against advanced cancer: A perspective from the Korean Integrative Cancer Center. J Biomed Biotechnol 2012: 874276, 2012.

11. Lee JO, Moon JW, Lee SK, Kim SM, Kim N, Ko SG, Kim HS and Park SH: Rhus verniciflua extract modulates survival of MCF-7 breast cancer cells through the modulation of AMPK-pathway. Biol Pharm Bull 37: 794-801, 2014.

12. Kim JH, Kim HP, Jung CH, Hong MH, Hong MC, Bae HS, Lee SD, Park SY, Park JH and Ko SG: Inhibition of cell cycle progression via $\mathrm{p} 27^{\mathrm{Kip} 1}$ upregulation and apoptosis induction by an ethanol extract of Rhus verniciflua Stokes in AGS gastric cancer cells. Int J Mol Med 18: 201-208, 2006.

13. Son YO, Lee KY, Lee JC, Jang HS, Kim JG, Jeon YM and Jang YS: Selective antiproliferative and apoptotic effects of flavonoids purified from Rhus verniciflua Stokes on normal versus transformed hepatic cell lines. Toxicol Lett 155: 115-125, 2005.
14. Kim JE, Lee SY, Lee JS, Park YL and Whang KU: Clinical features of systemic contact dermatitis due to the ingestion of lacquer in the Province of Chungcheongnam-do. Ann Dermatol 24: 319-323, 2012.

15. Ma WJ, Cheng S, Campbell C, Wright A and Furneaux H: Cloning and characterization of HuR, a ubiquitously expressed Elav-like protein. J Biol Chem 271: 8144-8151, 1996.

16. Seger R and Krebs EG: The MAPK signaling cascade. FASEB J 9: 726-735, 1995.

17. Lee SH, Kim KS, Choi WC and Yoon SW: Successful outcome of advanced pulmonary adenocarcinoma with malignant pleural effusion by the standardized Rhus verniciflua Stokes extract: A case study. Explore 5: 242-244, 2009.

18. Elmore S: Apoptosis: A review of programmed cell death. Toxicol Pathol 35: 495-516, 2007.

19. Parrish AB, Freel CD and Kornbluth S: Cellular mechanisms controlling caspase activation and function. Cold Spring Harb Perspect Biol 5: 1-6, 2013.

20. Kato K, Yamanouchi D, Esbona K, Kamiya K, Zhang F, Kent KC and Liu B: Caspase-mediated protein kinase C- $\delta$ cleavage is necessary for apoptosis of vascular smooth muscle cells. Am J Physiol Heart Circ Physiol 297: H2253-H2261, 2009.

21. Adams JM and Cory S: The Bcl-2 protein family: Arbiters of cell survival. Science 281: 1322-1326, 1998.

22. Festjens N, van Gurp M, van Loo G, Saelens $X$ and Vandenabeele P: Bcl-2 family members as sentinels of cellular integrity and role of mitochondrial intermembrane space proteins in apoptotic cell death. Acta Haematol 111: 7-27, 2004.

23. Gross A, McDonnell JM and Korsmeyer SJ: BCL-2 family members and the mitochondria in apoptosis. Genes Dev 13: 1899-1911, 1999.

24. Zha H, Aimé-Sempé C, Sato T and Reed JC: Proapoptotic protein Bax heterodimerizes with $\mathrm{Bcl}-2$ and homodimerizes with Bax via a novel domain (BH3) distinct from $\mathrm{BH} 1$ and $\mathrm{BH} 2$. J Biol Chem 271: 7440-7444, 1996.

25. Adachi M, Higuchi H, Miura S, Azuma T, Inokuchi S, Saito H, Kato $\mathrm{S}$ and Ishii $\mathrm{H}$ : Bax interacts with the voltage-dependent anion channel and mediates ethanol-induced apoptosis in rat hepatocytes. Am J Physiol Gastrointest Liver Physiol 287: G695-G705, 2004.

26. Banerjee $\mathrm{J}$ and Ghosh S: Bax increases the pore size of rat brain mitochondrial voltage-dependent anion channel in the presence of tBid. Biochem Biophys Res Commun 323: 310-314, 2004.

27. Choi EY, Shin KC, Lee J, Kwon TK, Kim S and Park JW: Treatment with a small synthetic compound, KMU-193, induces apoptosis in A549 human lung carcinoma cells through p53 up-regulation. Asian Pac J Cancer Prev 16: 5883-5887, 2015.

28. Fridman JS and Lowe SW: Control of apoptosis by p53. Oncogene 22: 9030-9040, 2003.

29. Liu CJ, Zhang XL, Luo DY, Zhu WF, Wan HF, Yang JP, Yang XJ and Wan FS: Exogenous p53 upregulated modulator of apoptosis (PUMA) decreases growth of lung cancer A549 cells. Asian Pac J Cancer Prev 16: 741-746, 2015.

30. Ruvinsky I and Meyuhas O: Ribosomal protein S6 phosphorylation: From protein synthesis to cell size. Trends Biochem Sci 31: 342-348, 2006.

31. Wenlei B, Xiyan H, Xu Z, Yan L, Yuhao C, Yanfeng W and Zhigang W: Molecular characterization and expression analysis of ribosomal protein S6 gene in the Cashmere goat (Capra hircus). Asian-Australas J Anim Sci 26: 1644-1650, 2013.

32. Poomakkoth N, Issa A, Abdulrahman N, Abdelaziz SG and Mraiche F: p90 ribosomal S6 kinase: A potential therapeutic target in lung cancer. J Transl Med 14: 14, 2016. 